\title{
Rapid growth of international collaboration from articles indexed in Scopus database by researchers in Korea from 2006 to 2015
}

\author{
Yeonok Chung' ${ }^{1}$ Kihong Kim² \\ ${ }^{1}$ Department of Social Welfare, Jangan University, Hwaseong; ' 2Department of Physics, Ajou University, Suwon, Korea
}

\begin{abstract}
It aimed at analyzing the trends of international collaboration from articles indexed in Scopus by researchers in Korea from 2006 to 2015. The number of articles coauthored by researchers in Korea and those in selected foreign countries was obtained from document searches of the Scopus database. The growth of research collaboration in various academic disciplines was also studied. There were 22 countries which produced over 2,000 papers in collaboration with researchers in Korea during the ten-year period between 2006 and 2015. The average of the average annual growth rate taken over these 22 countries was 12.9\%. In 9 additional Asian, Latin American, and African countries, more rapid growth of international research collaboration was clearly seen. Though research collaboration is most active in the field of physics and astronomy with most countries, it was found that the growth of collaboration in medicine was most remarkable in Southeast Asian countries. It may be originated from the intimate relationship between Korea and Southeast Asia and the leadership of Korean physicians in that region.
\end{abstract}

Keywords

Bibliometrics; Internationality; Internet; Republic of Korea; Research personnel

Received: January 31, 2017 Accepted: February 8, 2017

\section{Correspondence to Kihong Kim} khkim@ajou.ac.kr

ORCID

Yeonok Chung

http://orcid.org/0000-0003-0008-5772 Kihong Kim

http://orcid.org/0000-0001-9965-3535

\section{Introduction}

In recent years, there has been a rapid increase in international collaborations in research and development [1,2]. It may be originated from a variety of reasons, such as the movement of globalization, the development in communication, information, and transportation technologies, and the general increase of human interactions across the world. One crucial factor may be the development of the internet which made it possible to have very efficient and fast academic communication among researchers. The internet made not only international but also domestic collaboration much easier, which resulted in the substantial increase of the average number of authors per paper [3]. In this article, we aimed to study this phenomenon using the yearly num- 
ber of research publications coauthored by researchers in Korea and those in 31 foreign countries, which were published from 2006 to 2015 and indexed in the Scopus database. We also searched for the factors causing the growth of international collaboration. The results will be able to show the trends of international collaboration by researchers in Korea.

\section{Methods}

We used the Scopus database to find the number of publications jointly written by researchers in Korea and those in foreign countries. The Scopus database was searched in January 9, 2017. When using the document search function of the Scopus database, we restricted the search to three types of documents, which were "articles", "reviews", and "conference papers", and to two affiliation countries, "Korea" and "each designated country". The numbers of documents published each year from " 2006 " to "2015" and the total number of documents during the ten-year period were retrieved. For example, the query string, (AFFIL COUNTRY(Korea) AND AFFILCOUNTRY(Japan)) AND
DOCTYPE (ar OR re OR cp) AND PUBYEAR=2006, gives the number of articles, reviews, and conference papers jointly written by researchers in Korea and those in Japan in 2006. The Scopus database provides the search data which break down the number of documents by subject areas. We also retrieved these numbers to find out the changes in each subject area separately. The search was performed for bi-national collaborations between Korea and another country. Multi-national collaborations by researchers from more than two countries were not investigated.

Using the number of documents published each year, we calculated the annual growth rate (AGR) for the year $(N+1)$ defined by

$$
\text { AGR }(N+1)=\frac{\text { Number for year }(N+1)-\text { Number for year } N}{\text { Number for year } N} \text {. }
$$

By taking the average of this quantity from 2007 to 2015, we also calculated the average annual growth rate (AAGR) for each country. In addition, we calculated the compounded annual growth rate (CAGR), which was defined in the present

Table 1. The yearly number of documents coauthored by researchers in Korea and those in the country designated in the first column from 2006 to 2015

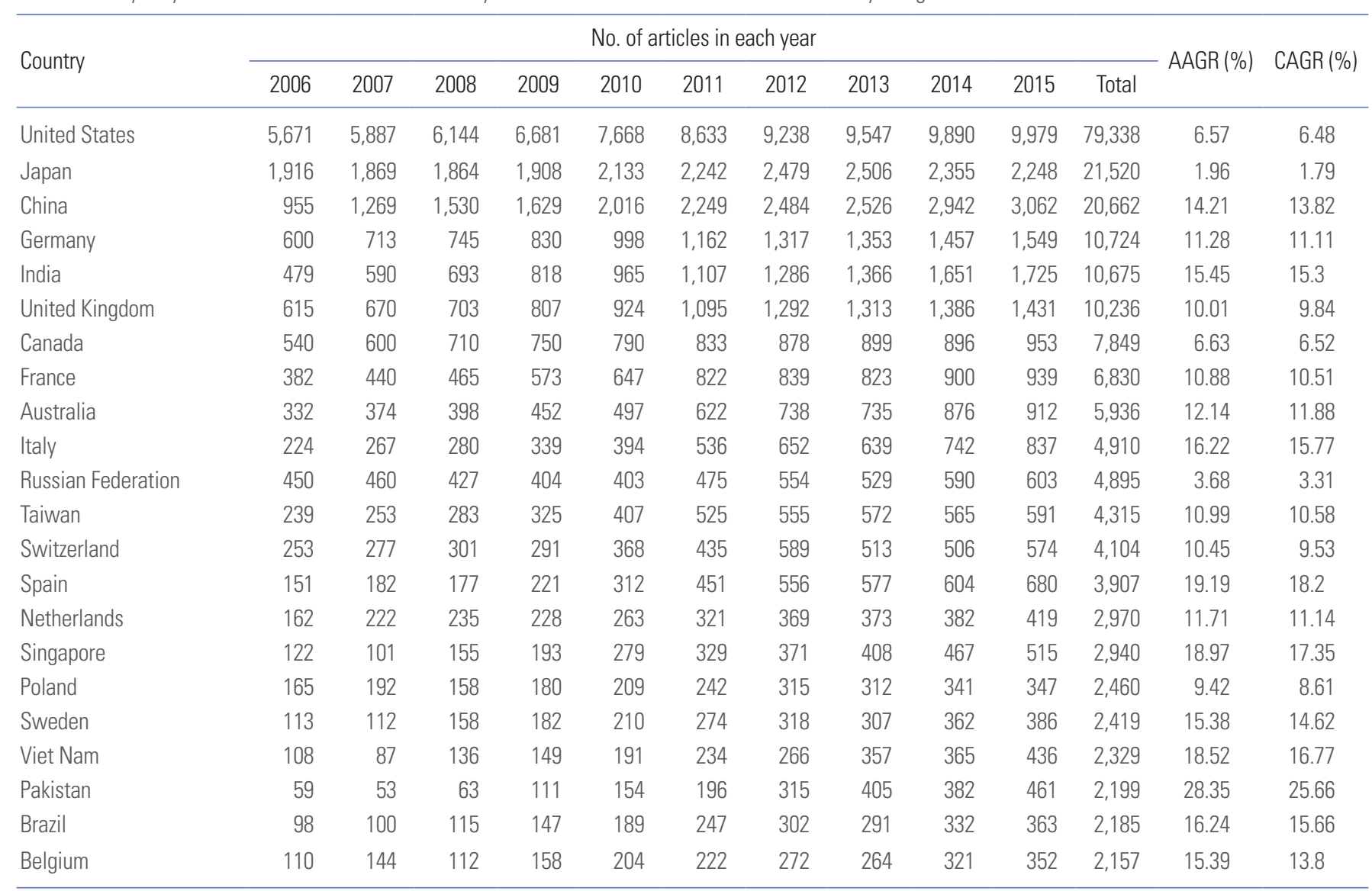

AAGR, average annual growth rate; CAGR, compounded annual growth rate. 
case by

$$
\text { CAGR }=\left(\frac{\text { Number in } 2015}{\text { Number in 2006 }}\right)^{1 / 9}-1
$$

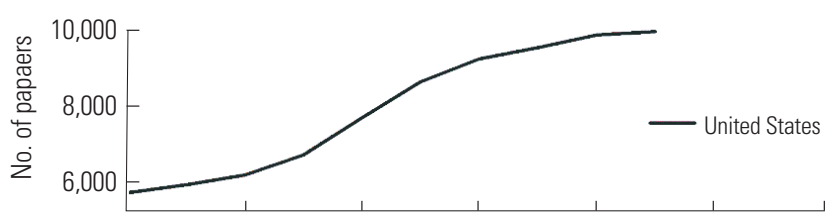

A

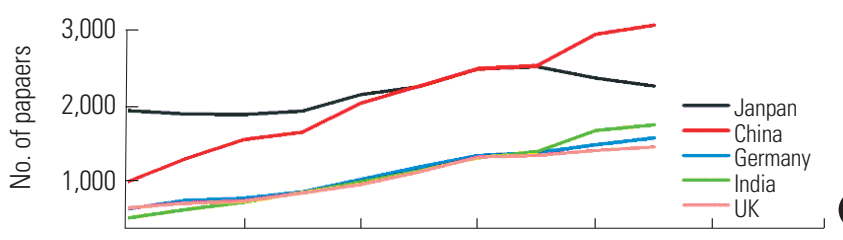

B
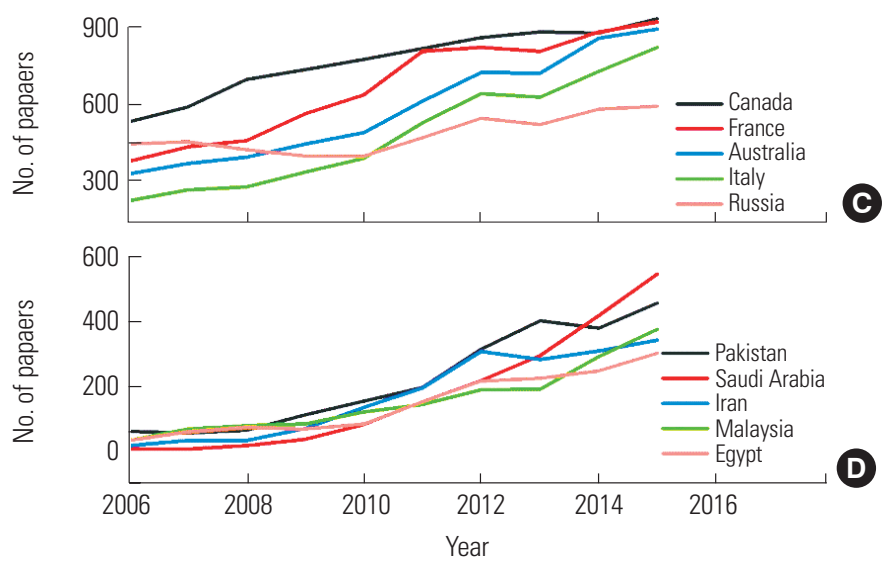

Fig. 1. The number of papers coauthored by researchers in Korea and those in the country designated in the figure in each year from 2006 to 2015 plotted versus publication year. In (A), the United States and in $(B)$, the countries which produced the 2nd to 6th largest number of papers are shown, while, in (C), those which produced the 7th to 11th largest number of papers are shown. In (D), the countries which had the top five average annual growth rate among all countries studied are shown.

\section{Results}

Our main search results are summarized in Tables 1 and 2. In Table 1, we showed the yearly number of documents coauthored by researchers in Korea and those in the country designated in the first column from 2006 to 2015. We also showed the total number of documents during the ten-year period, the AAGR, and the CAGR. Twenty two countries
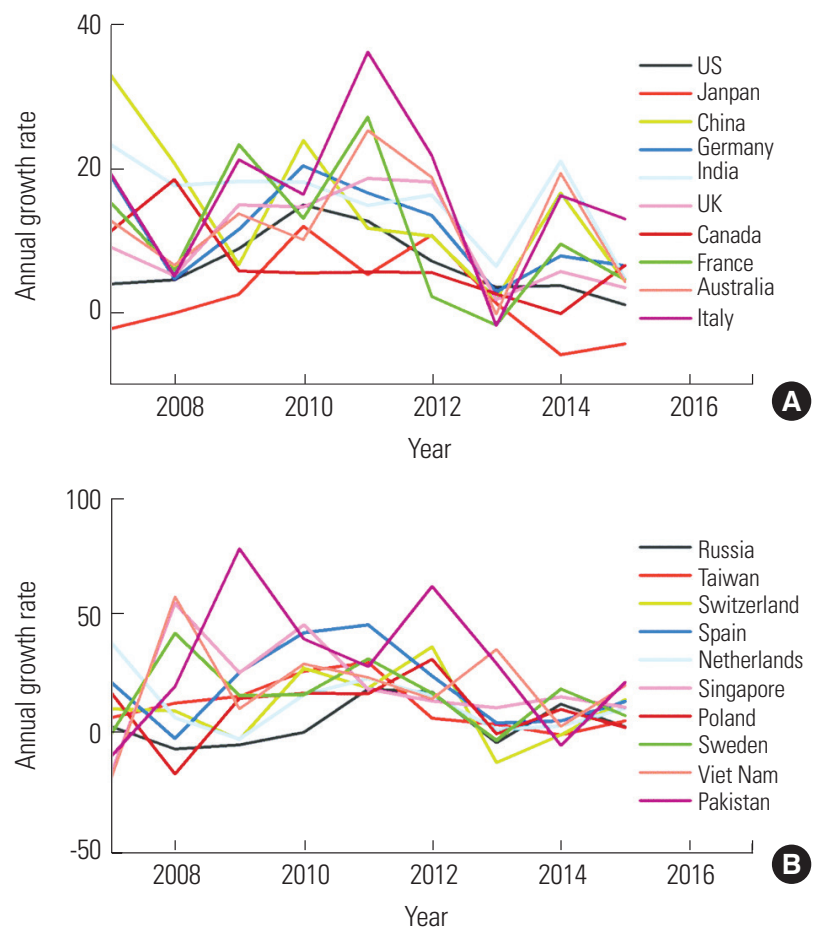

Fig. 2. Annual growth rate for (A) the top 10 and (B) the 11 th to 20 th countries which produced the largest number of documents in collaboration with Korea plotted versus year.

Table 2. The yearly number of documents coauthored by researchers in Korea and those in the country designated in the first column from 2006 to 2015

\begin{tabular}{|c|c|c|c|c|c|c|c|c|c|c|c|c|c|}
\hline \multirow{2}{*}{ Country } & \multicolumn{11}{|c|}{ No. of articles in each year } & \multirow{2}{*}{$\operatorname{AAGR}(\%)$} & \multirow{2}{*}{ CAGR $(\%)$} \\
\hline & 2006 & 2007 & 2008 & 2009 & 2010 & 2011 & 2012 & 2013 & 2014 & 2015 & Total & & \\
\hline Saudi Arabia & 3 & 3 & 15 & 34 & 81 & 152 & 218 & 296 & 420 & 552 & 1,773 & 100.56 & 78.5 \\
\hline Iran & 14 & 30 & 31 & 68 & 134 & 195 & 309 & 284 & 310 & 345 & 1,720 & 50.04 & 42.77 \\
\hline Thailand & 53 & 59 & 94 & 108 & 122 & 150 & 171 & 247 & 307 & 342 & 1,653 & 23.95 & 23.02 \\
\hline Hong Kong & 65 & 96 & 107 & 103 & 147 & 169 & 216 & 218 & 240 & 257 & 1,618 & 17.67 & 16.5 \\
\hline Malaysia & 31 & 67 & 76 & 83 & 120 & 143 & 189 & 191 & 292 & 378 & 1,570 & 35.34 & 32.03 \\
\hline Mexico & 89 & 89 & 146 & 146 & 183 & 243 & 266 & 218 & 238 & 267 & 1,887 & 14.99 & 12.98 \\
\hline Colombia & 33 & 37 & 55 & 54 & 81 & 127 & 151 & 136 & 146 & 156 & 976 & 20.99 & 18.84 \\
\hline Egypt & 30 & 58 & 72 & 66 & 82 & 152 & 216 & 225 & 248 & 304 & 1,452 & 33.09 & 29.35 \\
\hline South Africa & 21 & 27 & 28 & 35 & 46 & 73 & 102 & 108 & 126 & 140 & 706 & 24.53 & 23.47 \\
\hline
\end{tabular}

AAGR, average annual growth rate; CAGR, compounded annual growth rate. 
which produced more than 2,000 documents in collaboration with Korea were United States, Japan, China, Germany, India, United Kingdom, Canada, France, Australia, Italy, Russian Federation, Taiwan, Switzerland, Spain, Netherlands, Singapore, Poland, Sweden, Viet Nam, Pakistan, Brazil, and Belgium in the decreasing order of the number of publications. Except for Japan, which showed a low AAGR of 1.96\%, all countries showed a substantial growth in the number of pub- lications during the ten-year span. The average of the AAGR taken over the 22 countries listed was $12.9 \%$. The CAGR is consistently a little smaller than the AAGR. The discrepancy between the AAGR and the CAGR is larger when the yearly fluctuation in the AGR is larger.

In Table 2, we showed the results obtained for 9 additional countries from Asia, North America, South America, and Africa, which include Saudi Arabia, Iran, Thailand, Hong Kong,

Table 3. Number of documents from 2006 to 2015 coauthored by researchers in Korea and those in the designated country in the top five fields

\begin{tabular}{|c|c|c|c|c|c|}
\hline Country & 1st field & 2nd field & 3rd field & 4th field & 5th field \\
\hline United States & Eng $(18,416)$ & Med $(17,250)$ & Phys $(16,490)$ & Bio $(13,806)$ & Mat $(11,986)$ \\
\hline Japan & Phys $(6,604)$ & Eng $(4,370)$ & Mat $(3,992)$ & $\operatorname{Med}(3,513)$ & Bio $(3,387)$ \\
\hline China & Phys $(5,614)$ & Eng $(4,720)$ & Mat $(3,713)$ & Med $(3,089)$ & Bio $(2,912)$ \\
\hline Germany & Phys $(5,051)$ & $\operatorname{Med}(1,776)$ & Eng $(1,683)$ & Mat $(1,578)$ & Bio $(1,333)$ \\
\hline India & Phys $(4,064)$ & Mat $(2,815)$ & Chem $(2,284)$ & Eng $(2,201)$ & Chem Eng $(1,306)$ \\
\hline United Kingdom & Phys $(3,806)$ & $\operatorname{Med}(2,063)$ & Eng $(1,922)$ & $\operatorname{Bio}(1,369)$ & Mat $(1,220)$ \\
\hline Canada & Phys $(1,918)$ & $\operatorname{Med}(1,740)$ & Eng $(1,504)$ & Bio $(1,218)$ & Comp $(1,056)$ \\
\hline France & Phys $(3,327)$ & Eng $(1,059)$ & $\operatorname{Med}(1,049)$ & Mat (815) & Bio (720) \\
\hline Australia & Phys $(1,478)$ & $\operatorname{Med}(1,434)$ & Eng $(1,143)$ & Mat (834) & Bio (776) \\
\hline Italy & Phys $(2,443)$ & $\operatorname{Med}(1,160)$ & Bio (625) & Eng (618) & Earth (373) \\
\hline Russian Federation & Phys $(3,417)$ & Eng (667) & Mat (563) & Chem (317) & Earth (286) \\
\hline Taiwan & Phys $(1,967)$ & $\operatorname{Med}(1,025)$ & Eng (525) & Bio (414) & Comp (348) \\
\hline Switzerland & Phys $(2,330)$ & Med (712) & Eng (493) & Bio (401) & Mat (383) \\
\hline Spain & Phys $(2,027)$ & $\operatorname{Med}(773)$ & Eng (490) & Bio (462) & Earth (351) \\
\hline Netherlands & Phys $(1,303)$ & Med (748) & Bio (418) & Eng (332) & Earth (180) \\
\hline Singapore & Med (937) & Eng (718) & Bio (581) & Comp (478) & Mat (411) \\
\hline Poland & Phys $(1,578)$ & Med (332) & Eng (236) & Bio (205) & Earth (187) \\
\hline Sweden & Phys $(1,108)$ & Med (544) & Bio (410) & Eng (282) & Chem (208) \\
\hline Viet Nam & Eng (671) & Phys (535) & Mat (474) & Chem (420) & Med (381) \\
\hline Pakistan & Phys (864) & Eng (367) & Comp (278) & Agri (264) & Math (256) \\
\hline Brazil & Phys $(1,394)$ & $\operatorname{Med}(426)$ & Eng (193) & Bio (176) & Earth (108) \\
\hline Belgium & Phys $(1,072)$ & $\operatorname{Med}(471)$ & Eng (321) & Bio (253) & Mat (192) \\
\hline Saudi Arabia & Chem (451) & Mat (441) & Phys (426) & Eng (387) & Chem Eng (285) \\
\hline Iran & Phys (713) & Math (354) & Eng (353) & Mat (250) & Med (176) \\
\hline Thailand & Med (647) & Phys (366) & Bio (228) & Eng (213) & Agri (193) \\
\hline Hong Kong & Med (586) & Eng (266) & Comp (236) & Bio (210) & Phys (189) \\
\hline Malaysia & $\operatorname{Med}(450)$ & Eng (382) & Phys (337) & Comp (221) & Bio (184) \\
\hline Mexico & Phys $(1,333)$ & $\operatorname{Med}(237)$ & Eng (184) & Earth (131) & Mat (110) \\
\hline Colombia & Phys (751) & Med (137) & Eng (68) & Math (59) & Bio (54) \\
\hline Egypt & Phys (614) & Chem (289) & Eng (288) & Mat (252) & Med (179) \\
\hline South Africa & Phys (287) & $\operatorname{Med}(176)$ & Eng (108) & Earth (106) & Bio (76) \\
\hline
\end{tabular}

Eng, engineering; Med, medicine; Phys, physics and astronomy; Bio, biochemistry, genetics and molecular biology; Mat, materials science; Chem, chemistry; Chem Eng, chemical engineering; Comp, computer science; Earth, earth and planetary sciences; Agri, agricultural and biological sciences; Math, mathematics. 

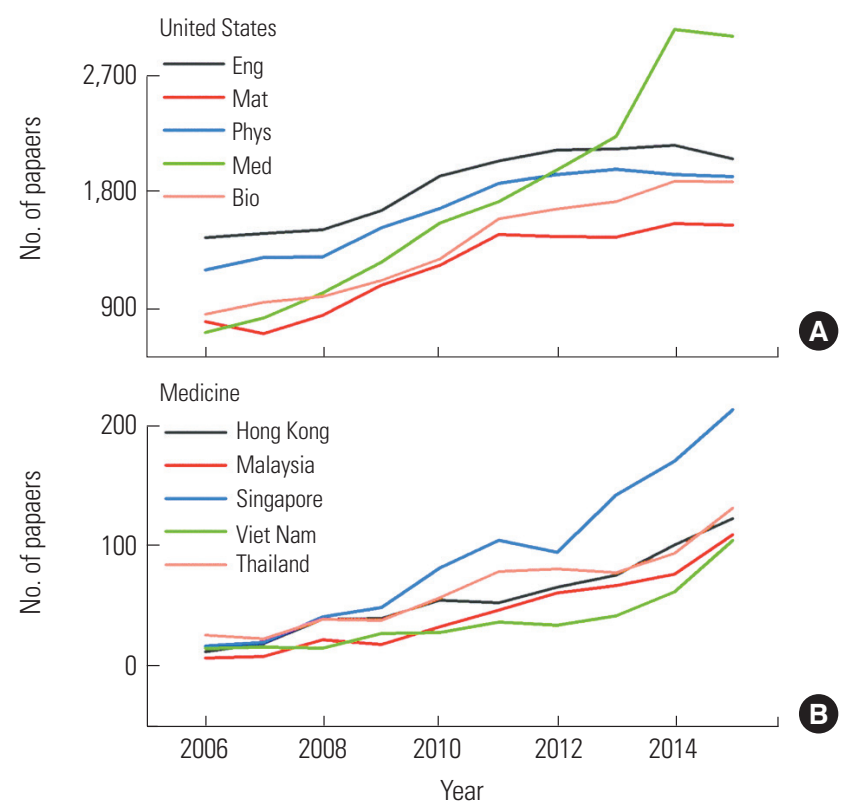

Fig. 3. (A) The number of papers coauthored by researchers in Korea and those in the United States in each year from 2006 to 2015 in the top five academic fields which produced the largest number of papers plotted versus publication year. (B) The number of papers coauthored by researchers in Korea and those in the countries designated in the figure in each year from 2006 to 2015 in the field of medicine plotted versus publication year. Eng, engineering; Mat, materials science; Phys, physics and astronomy; Med, medicine; Bio, biochemistry, genetics and molecular biology.

Malaysia, Mexico, Colombia, Egypt, and South Africa. These countries produced the largest number of publications in collaboration with Korea in each continent, except for those already shown in Table 1 . Their growth rates were, on the average, substantially larger than those listed in Table 1.

In Fig. 1, we showed the number of papers coauthored by researchers in Korea and those in some selected countries in each year from 2006 to 2015 versus publication year. In Fig. $1 \mathrm{~A}, 1 \mathrm{~B}$, and $1 \mathrm{C}$, the top 11 countries which produced the largest number of papers are shown, while, in Fig. 1D, the countries which showed the top five AAGRs are shown. Except for Japan and Russian Federation, the trend of rapid growth was clearly seen.

In Fig. 2, the AGR for the top 20 countries which produced the largest number of papers in collaboration with Korea is plotted versus year. We remind the reader that, for example, the AGR for 2007 is computed from the number of papers published in 2006 and that in 2007. The yearly fluctuation of the growth rate is observed to be rather large and sometimes the growth rate is negative. From the 20 curves shown in this figure, we notice that the growth rates for many countries dropped rather rapidly between 2012 and 2013 and also between 2007 and 2008. Similar behavior is observed for other countries not shown in this figure.

We also examined the dependence of the growth of international collaboration on academic disciplines. In Table 3 , the total number of documents from 2006 to 2015 coauthored by researchers in Korea and those in the country designated in the first column in the top five academic fields which produced the largest number of documents in each country. In many countries, physics and astronomy, medicine, engineering, materials science, and biochemistry, genetics and molecular biology are the dominant fields with the largest number of documents. Physics and astronomy is the most dominant field with the largest number of documents in 24 countries out of the total 31 countries. In five countries which include Colombia, Mexico, Russian Federation, Poland, and Brazil, the portion of the documents in physics and astronomy was more than $60 \%$. Medicine is the second largest field with the largest number in 4 countries and the second largest number in 17 countries.

In Fig. 3A, we plotted the number of papers coauthored by researchers in Korea and those in the United States in each year from 2006 to 2015 in the top five academic fields which produced the largest number of papers versus publication year. We found that there was considerable growth in all five fields, with the growth in medicine being particularly rapid. In Fig. 3B, we showed the number of papers coauthored by researchers in Korea and those in the five Southeast Asian countries designated in the figure in each year from 2006 to 2015 in the field of medicine versus publication year. The rapid growth in all five countries is remarkable.

\section{Discussion}

These results show that the rapid increase of international collaborations between Korean researchers and foreign researchers is a general trend, which applies to a very large number of countries in the world. That the United States is the top ranking collaborative country is not surprising because it has been the most favorite country for Korean students and young researchers to visit to study abroad and the number of visits has been outstanding. Out of the top five collaborative countries, India and China showed the 1st and 2nd largest growth rates. This is perhaps related to the large influx of graduate students and postdoctoral researchers from these countries into Korean universities and research institutes in the recent decade. The same reasoning may be applied to Pakistan, which showed the largest AAGR in Table 1. The extremely rapid growth rate for Saudi Arabia listed in Table 2 is especially remarkable. This seems to be due to the government policy drive to enhance research collaborations between the two countries.

In Table 3, we examined the dependence of the growth of 
international collaboration on academic disciplines. The case of Colombia, where physics and astronomy documents take up $77 \%$ of the total, is particularly interesting. We found that there were 10 countries other than Korea and Colombia, each of which was affiliated with more than $70 \%$ of the total 976 documents produced by collaborations between Korea and Colombia. This implies that a great majority of documents were produced through international collaborations among many countries. We suspect that a very large number of documents are in the area of experimental high energy physics, in which multinational collaborations are quite common. On the other hand, it is quite interesting to notice that the four countries with the largest number of documents in medicine are all Southeast Asian countries, namely, Singapore, Thailand, Hong Kong, and Malaysia. Saudi Arabia is unique in that the field with the largest number of documents is chemistry, in contrast to all other countries. This supports our suspicion that the collaboration between Korea and Saudi Arabia has been driven by external policies to enhance research collaborations mainly in the fields related to petrochemical industry.

In Fig. 2, we mentioned that the growth rates for many countries dropped between 2012 and 2013 and between 2007 and 2008. We think this may be due to the global economic recession which occurred during the same period and a corresponding decrease in research funding in many countries.

In conclusion, the rapid growth of international research collaboration was clearly seen in almost all cases studied here. The overall increase might be attributed to the movement of globalization, the development in communication and transportation technologies, and the development of the internet. Though research collaboration was most active in the field of physics and astronomy in most countries, it was found that, in many countries in Southeast Asia, the growth of collaboration in medicine was most remarkable. It may be originated from the intimate relationship between Korea and Southeast Asia and the leadership of Korean physicians in that region.

\section{Conflict of Interest}

No potential conflict of interest relevant to this article was reported.

\section{References}

1. Witze A. Research gets increasingly international. Nature 2016 Jan 19 [Epub]. http://dx.doi.org/10.1038/nature.2016.19198

2. Wagner CS, Park HW, Leydesdorff L. The continuing growth of global cooperation networks in research: a conundrum for national governments. PLoS One 2015;10: e0131816. http://dx.doi.org/10.1371/journal.pone.0131816

3. Jang H, Kim K, Huh S, Kim H. Increasing number of authors per paper in Korean science and technology papers. Sci Ed 2016;3:80-9. https://doi.org/10.6087/kcse.70 